THEORIA ET HISTORIA SCIENTIARUM,VOL. V11, № 2

Ed. Nicolas Copernicus University 2003

David Livingstone Smith, Ph.D.*

\title{
The evolution of unconscious social cognition and communication
}

Contemporary evolutionary theory states that those genes that enhance their own reproductive success spread through populations. Amongst sexually reproducing taxa, genes proliferate by (a) building organisms that survive at least to reproductive age and (b) are sufficiently attractive to the opposite sex to have mating opportunities. Features or 'characters' of organisms that contribute to (a) and (b) are described as 'fitness enhancing' or 'adaptive'.

Adaptation is always relative to a given environment. Characters that are adaptive in one environment may be disadvantageous in another. An environmental fact that forces evolutionary change is called a 'selection pressure'. For example, fair skin may have been adaptive to human beings evolving in northern climates because it allowed them to capture sunlight to manufacture vitamin D. However, the present-day depletion of the ozone layer may make fair-skinned people vulnerable to lethal melanomas. Using this example, in the absence of extensive medical or preventative intervention, and all other relevant factors being equal, we could anticipate an evolutionary shift towards darker-skinned populations because the damaging effects of ultraviolet radiation exerts a selection pressure limiting the reproductive success of fair-skinned individuals.

The speed of evolution is proportional to the rate of reproduction. This fact has very important implications for understanding our species. The relatively slow pace of human evolution entails that our bodies and minds are adapted to

* Address for correspondence: University of New England, 11 Hills Beach Road, Biddeford, ME 04005 USA. Email: dsmith@une.edu 
ancestral physical and social environments, the Environment of Evolutionary Adaptedness (or EEA). These ancestral environments were in many respects significantly different from those in which we currently reside. There is a burgeoning scientific literature showing that the activity of the human brain is constrained by its evolutionary history. We cannot do just anything with our brains. An infant's mind is not a tabula rasa, as the empiricist philosophers and behaviorist psychologists once asserted. It bears the imprint of six million years of hominid selection. We are bom, live and die with an evolved human nature consisting of dispositions that enhanced the reproductive success of our prehistoric ancestors.

Biologists use the term 'self-deception' to denote the motivated restriction of conscious access to psychological information. The predominant biological theory of selfdeception grew out attempts to explain altruism, biologically defined as any practice that enhances of the fitness of another at one's own cost. Hamilton (1963) demonstrated how a focus on the gene as the fundamental unit of selection elegantly explains the existence of altruism between genetically related individuals. Closely related kin, such as parents, offspring and siblings, have strong genetic similarities. Consider the relationship between parent and offspring. Parents donate $50 \%$ of their genes to each child. By making altruistic sacrifices for the benefit of a single child, a parent enhances the likelihood that $25 \%$ of his or her genes will be reproduced in each of their children's children. The life of a parent, then, has roughly the same genetic value as the life of two children and four grandchildren. Hamilton's rule, as it is called, generates numerous testable hypotheses. For example, it predicts that older mothers should be inclined to make greater sacrifices for their children than younger mothers because as a woman grows older her reproductive value declines relative to that of her children. It predicts that women are less likely to abort twins than to abort single embryos. It predicts that maternal grandmothers are likely to behave more altruistically towards their grandchildren than paternal grandfathers (with maternal grandfathers and paternal grandmothers lying in between the two extremes) because the inevitable uncertainty of paternity casts genetic relatedness into doubt. Hamilton's theory turned out to be an extraordinarily powerful tool for understanding animal behavior.

Trivers (1971) proposed a model for the evolution of altruism between unrelated individuals based on the principle of reciprocity. Given an appropriate relationship between costs and benefits, it makes sense to behave altruistically towards non-kin if they are likely to return the favor. However, having received a benefit, an organism may fail to reciprocate ('gross cheating'), or reciprocate only incompletely ('subtle cheating'). Altruism thus exerts a selection pressure for the evolution of cheating repertoires, and cheating is facilitated by deception. Both inter- and intra-specific 'dishonest signaling' are widespread in nature 
(Alexander, 1975; Dawkins, 1976; Dawkins \& Krebs, 1978; Otte, 1975; Wickler, 1968). Intra-specific cheating and deception seem particularly prevalent amongst the primates. Our closest non-human relatives, the chimpanzees, engage in sophisticated tactical deception of one another (de Waal, 1986; Miles, 1986).

Just as the proliferation of reciprocal altruism encouraged the evolution of deception, so intraspecific cheating facilitated the evolution of cognitive mechanisms for discriminative altruism and cheater detection, leading to an escalating co-evolutionary 'arms race' in which ever more sophisticated methods of deception were matched by ever more sophisticated methods of detecting and safeguarding against deception. The ruthless logic of natural selection sees to it that those organisms best able to identify deceit and take appropriate action to prevent being exploited are more likely to survive and reproduce than those who are not. The need to monitor cheating would obviously be most acute amongst highly social creatures living in fairly large groups. In such cases, the opportunities for cheating are so multifarious, and the social networks so intricate, that natural selection would be expected to favor strong social cognitive abilities. According to the thesis introduced by Humphrey (1976) and subsequently extended and developed by others (e.g., Byrne \& Whiten, 1988; Whiten \& Byrne, 1988; Whiten \& Byrne, 1997; Byrne, 1993; Byrne, 1994) this is precisely what occurred. Intraspecific conflict, deception, and the consequent need for sophisticated mind-leading abilities were significant driving forces behind the evolution of primate intelligence.

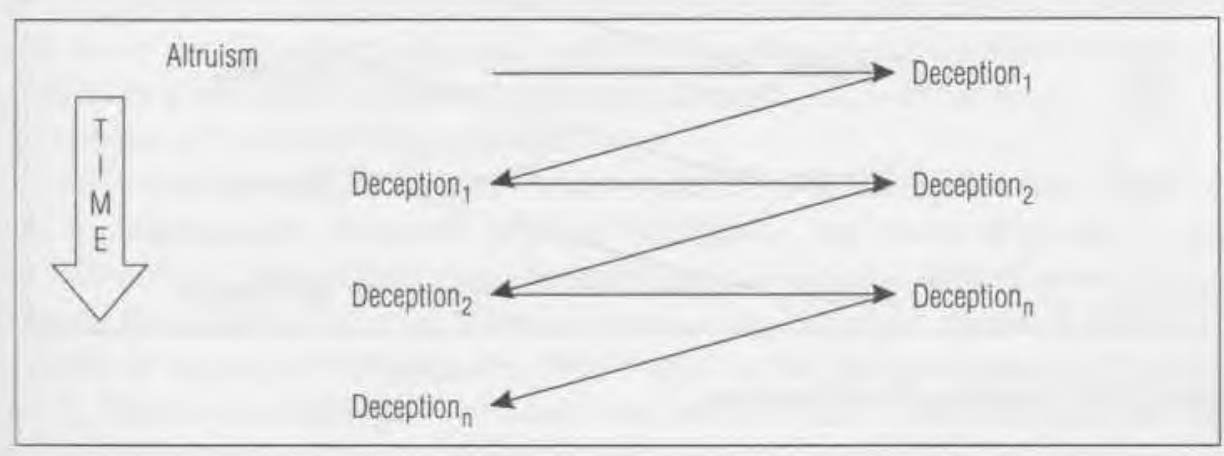

Figure 1: The Arms Race Between Deception and Detection

Each phase of this process creates selection pressures for the selection of the next in an ever-increasing spiral of interactional complexity until a point of equilibrium is reached at which intelligent deceivers become all too aware that they may be detected, and that severe and possibly fatal reprisals may result. 
Consciousness of one's own deceptive agenda, and the investment of others in detecting and deterring deception, produces anxiety which is involuntarily expressed by non-verbal signs such as slight modifications of posture, movement, and changes of voice pitch (Ekman, 1988; 1992) which increase the likelihood of being detected by organisms selected to be wary of intraspecific deception; this situation itself gives further cause for anxiety, and so on. Tri vers $(1976,1981,1985 b, 1988,1991,2000)$ argues that as the costs of conscious deception began to outweigh its benefits, the stage was set for the evolution of self-deception.

"In our own species we recognize that shifty eyes, sweaty palms, and croaky voices may indicate the stress that accompanies conscious knowledge of attempted deception. By becoming unconscious of its deception, the deceiver hides these signs from the observer. He or she can lie without the nervousness that accompanies deception" (Trivers, 1985b: 415416).

Trivers' self-deception, then, is a means to an end: the unconscious deception of others.

"Biologists propose that the overriding function of self-deception is the more fluid deception of others. That is, hiding aspects of reality from the conscious mind also hides these aspects more deeply from others. An unconscious deceiver is not expected to show signs of the stress associated with consciously trying to perpetrate deception" (Trivers, 1988: vii).

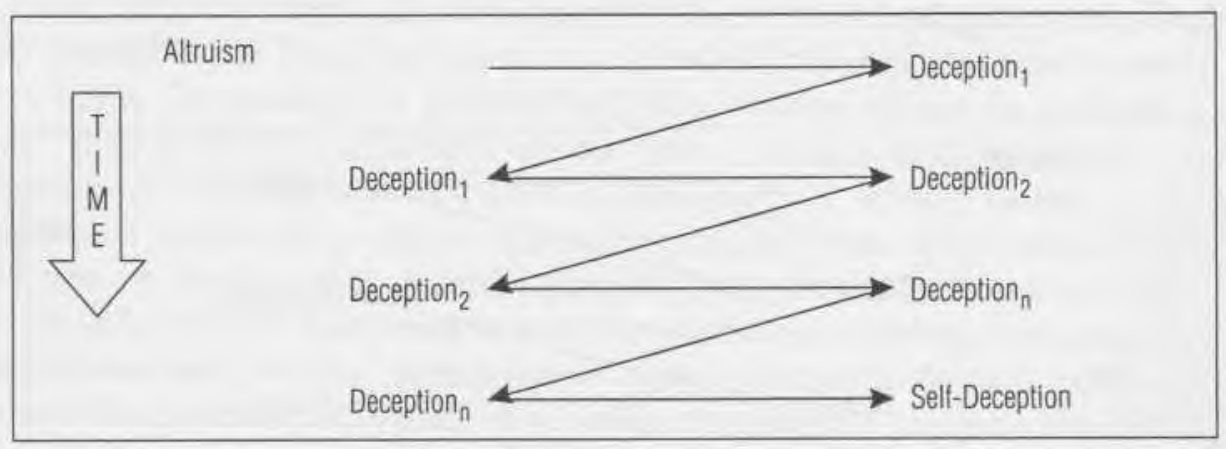

Figure 2: The Evolution of Self-Deception

\section{Self-deception and the evolution of unconscious social cognition}

Cognitive science teaches us that many automatic or routine processes are normally performed unconsciously. These processes are not actively excluded from awareness: they are structurally unconscious. Let us consider some ideas about the possible evolutionary underpinnings of conscious and unconscious cognition. 
'I operate on the assumption,' writes Trivers, 'that the split between conscious and unconscious evolved long before processes of deception and self-deception affected transfers of information between the two spheres.'

"The split itself probably related to energy efficiency: consciousness is an energyexpensive state that permits much more concentrated mental attention. We can imagine that over long periods of evolutionary time the brain either turned a whole series of functions over to the unconscious or left them there. Thus, under normal circumstances, we run our heart rate, our breathing, and other internal processes unconsciously. We only choose to be conscious about them...under conditions in which it makes sense to invest extra energy and faculties to scrutinize something carefully" (Trivers, 1991: 179).

Although the proposal that consciousness is more costly than unconsciousness is intuitively appealing, it has not as yet received unambiguous empirical corroboration, and is in fact rather difficult to test. However, the costliness claim can be detached from the proposition that consciousness was initially a response to the non-routine. Claxton (1994, 1997) argues that consciousness began as a state of hyper-arousal in response to threat or uncertainty.

There are two primal, recurrent situations of threat and uncertainty faced by animals in which consciousness is useful and perhaps even necessary: evading predators and stalking prey. Predation by its very nature involves the non-routine and unpredictable, and one false move can make the difference between life and death for either party to the interaction. Danger instantaneously galvanizes attention. A threatened animal becomes hyperaware. By the same token, an animal stalking its prey is fiercely attentive. Both predator and prey must anticipate the next move that the other will make, and to adjust their behavior accordingly. Let us take as a working hypothesis that consciousness evolved, at least in part, in the context of predator-prey relations.

After numerous iterations of the arms race between deception and detection which progressively enhanced primate intelligence, we arrive at genus Homo. At this point a remarkable situation developed in which 'other human beings became the principal hostile force of nature - the principal cause of failure to survive or reproduce' (Alexander, 1987: 78). As the Roman dramatist Plautus put it 'Homo homini lupus' - 'Man is a wolf to man'. Hominids solved the problem of interspecific predation by living in large cooperative groups (Dunbar, 1996) but this development also imposed costs. Linear increases in group size resulted in exponential bursts of social complexity.

"In a group of five individuals I have to keep track of a set of four relationships between myself and the other group members, but I have to monitor six additional relationships involving the other four individuals. In a group of twenty, I have to keep track of nineteen relationships between myself and fellow group members, and 171 third-party relationships involving the other nineteen members of the group. 
While my relationships with everyone else has increased roughly fivefold with the fivefold increase in group size, the number of third-party relationships I have to keep track of has increased almost thirtyfold" (Dunbar, 1996: 65).

The need to maintain social relations with coalition members imposed constraints on the size of pre-linguistic hominid groups. Primates maintain social cohesion largely by means of grooming, which in some species may occupy up to $20 \%$ of the day. Non-human primates find grooming intensely pleasurable, releasing cascades of endorphins in response to the fingers of their peers (Dunbar, 1996). Primates do not groom one another indiscriminately. They form 'grooming cliques' (subgroups of individuals that frequently groom one another), the members of which develop powerful coalitions. A primate in trouble can often rely on a member of its grooming clique to come to its aid. Dunbar (1996) discovered a correlation between primate group size, neocortex size (relative to overall brain mass) and mean grooming clique size. The correlation between group size and neocortex size is probably best explained by the cognitive demands made by the social complexity of larger groups. Group size correlates with grooming clique size because 'the animals have to form larger and larger grooming cliques to protect themselves from the harassment they invariably experience when living in large groups' (Ibid. 68). Given these correlations the human neocortex ratio would suggest that the size of primal groups of Homo sapiens consisted of about 150 individuals, a figure supported by archeological, anthropological and sociological data, however the robust correlation between group size and mean grooming clique size shows that if groups consisting of 150 individuals were to engage in the practice of grooming, the grooming cliques would be so large that a full $40 \%$ of their time would be taken up with this activity.

"But no species that has to earn its living in the real world could possibly sustain such a heavy investment of time in grooming. It would starve in the process.... Our ancestors must have faced a terrible dilemma: on the one hand there was relentless ecological pressure to increase group size, while on the other time-budgeting placed a severe upper limit on the size of groups they could maintain" (Dunbar, 1996: 78).

The evolution of language provided a solution when words replaced touch as the primary currency of social exchange. Language possesses two attributes that made it well suited to this task: (a) it enables intimate social intercourse with several individuals simultaneously, therefore greatly extending the size of grooming cliques without extending 'grooming' time, and (b) it permits exchanges of detailed social information, 'It allows you to say a great deal about yourself, your likes and dislikes, the kind of person you are; it also allows you to convey in numerous subtle ways something about your reliability as an ally or friend' (Dunbar, 1996:78).

The important role played by deception in hominid social life would presumably have promoted the heightening of social consciousness. Predation 
apparently provided a selection-pressure for the evolution of 'mind-reading' abilities: the ability to make 'inferences' about the intentions of the other - be it predator or prey - so as to predict its behavior (Barratt, 2000). The ability to detect and use subtle clues to anticipate the moment-to-moment hunting tactics of a hungry leopard were perhaps redeployed to detect signs of cheating and deception by conspecifics, and the cognitive adaptations responsible for predatory prowess were redeployed for social predation: the deception and exploitation of one's own kind. At this juncture, consciousness became chronic rather than episodic, because of the ongoing vigilance required to navigate complex social systems. I suggest that as the coevolutionary enhancement of hominid social intelligence and social complexity brought the faculty of consciousness to bear more and more on the struggles intrinsic to group life, conscious thought became an ongoing feature of the intricate Machiavellian choreography of social exchange.

Although the conscious mind is certainly capable of parallel processing, conscious cognition is, on the whole, strikingly linear and possesses very restricted infonnationbearing capacities. In contrast to this, unconscious processing seems to be massively parallel (Dennett, 1991) ${ }^{1}$. In other words, whereas conscious cognition is able to attend to only a few items at a time, unconscious cognition seems capable of attending to multiple items simultaneously. The focal character of consciousness is ideal for monitoring one-toone predator-prey relations but is ill suited for tracking the extremely complicated simultaneous interactions of group life. It seems obvious that consciousness would have been unable to cope with the novel cognitive demands placed upon it. I suggest that the evolutionary solution to the problem of conscious cognitive overload was to outsource a good deal of social cognition to the massively parallel unconscious apparatus ${ }^{2}$. Returning now to Trivers' theory of the origin of self-deception, we can recognize that this reconfiguration of the mind provided the additional adaptive advantage of permitting our ancestors to eliminate the telltale signs of stress that accompany conscious deception and therefore making it possible for them to deceive their fellows more effectively. On this analysis, unconscious social cognition possesses two primary adaptive functions: it eliminates cognitive overload and facilitates effective deception of others. It also involves two distinct but interlocking mental components: (a) unconscious social planning, including deception, manipulation and the like, and (b) unconscious social perception of the behavior of those with whom one engages

${ }^{1}$ It might be argued that my use of Dennett begs more questions than it answers because I do not provide a truly Dennettian account of conscious seriality as the simulation of a serial processor by the parallel architecture of the brain. Because of limitations of space this issue will not be discussed in the present paper, but will be dealt with in a paper now in preparation.

${ }^{2}$ A version of this thesis was suggested by Langs $(1995,1996)$. 
in social intercourse. This second feature is actually implied by, although not explicitly stated in, Trivers' theory because effective deception requires a perceptual feedback loop for monitoring the moment-to-moment responses of the victim. Attempting to deceive without being informed by perceptual feedback would be like trying to play a game of chess without knowing what moves your adversary is making. The logic of Trivers' theory demands that this occurs unconsciously, so as not to short-circuit the adaptive advantages of self-deception.

One implication of this hypothesis, which we will have occasion to revisit in the example provided below, is that unconscious social perception should be strongly biased in favor of its owner's interests (because its function is ultimately to enhance its owner's reproductive success), and we should also expect it to be somewhat 'paranoid' with respect to the malicious intentions of others. Nature favors the ability to make quick and dirty decisions. When a twig snaps somewhere in the underbrush it is better to flee from what you suspect is a tiger than to wait and see what beast saunters out of the bushes.

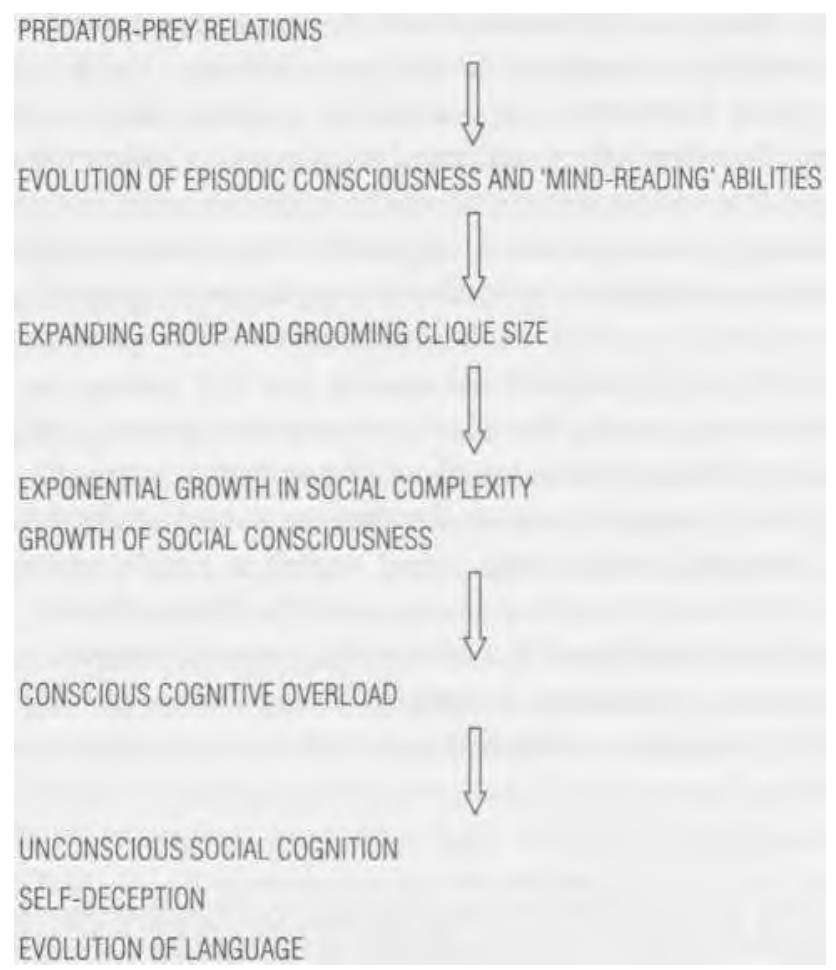

Figure 3: The Evolution of Unconscious Social Cognition 
The intimate intertwining of expanding group size, social-cognitive architecture and the evolution of language indicates that there might some special connection between speech and the structure of consciousness. Trivers (1981) suggests that the verbal module, which is in a sense the public face of the mind, became specialized for promoting falsehood both to oneself and to others. Although it is perhaps possible that the evolution of selfdeception preceded the evolution of language, it seems beyond doubt that the emergence of language greatly enhanced our facility both to deceive and to self-deceive (Trivers, 1991).

\section{Are we unconscious mind-readers?}

Given the socially embedded nature of the form of unconscious cognition described above, one would anticipate that it would be most readily studied in naturalistic or quasinaturalistic conversational settings involving conflicts and confluences of interest and emotionally significant interactions. Both one-to-one psychoanalysis and small groups (' $\mathrm{T}$ groups') used for the study of group dynamics conform to these criteria, and both have generated ideas and research pertinent to the hypotheses that I have presented. The use of psychoanalytic and small group data for this purpose does not, of course, entail any commitment to either psychoanalytic or group-relations theory.

Freud occasionally described unconscious perception in the psychoanalytic situation. Here is an example from 'Recommendations to physicians practicing psycho-analysis' (1912).

"To put it in a fonnula: he [the analyst] must turn his own unconscious like a receptive organ towards the transmitting unconscious of the patient. He must adjust himself to the patient as a telephone receiver is adjusted to the transmitting microphone. Just as the receiver converts back into sound waves the electric oscillations in the telephone line which were set up by sound waves, so the doctor's unconscious is able, from the derivatives of the unconscious which are transmitted to him, to reconstruct that unconscious, which has determined the patient's free-associations" (115-116).

A remark published the following year is even more explicit: $\mathrm{T}$ have had good reason for asserting that everyone possesses in his own unconscious an instrument with which he can interpret the utterances of the unconscious in other people' (1913a: 320). In the same year he claimed that this faculty is not confined to members of the psychoanalytic profession, but is a universal design feature of the human mind:

"Psycho-analysis has shown us that everyone possesses in his unconscious mental activity an apparatus which enables him to interpret other people's 
reactions, that is, to undo the distortions which other people have imposed upon the expression of their feelings" (1913b: 139).

Langs, a contemporary psychoanalyst, developed a systematic approach to understanding unconscious perception in the clinical situation (e.g. Langs, 1978, 1979, 1980, 1981, 1985, 1992a, 1992b), claiming that psychotherapy patients unconsciously monitor and interpret the behavior of their therapists, particularly with respect to fundamental relational parameters. This process of 'unconscious meaning analysis' (Dorpat \& Miller, 1992) is rapid, incisive and effected by a domain-specific cognitive module, the output of which is expressed only indirectly by means of metaphors and analogies embedded in manifestly unrelated narratives.

Langs' emphasis on a fundamental distinction between narrative and nonnarrative communication coheres with work in cognitive science suggesting that narrative and nonnarrative modes of communication involve distinct forms of cognition (e.g. Bruner, 1986; Bucci, 1997). Narrative may be the most ancient form of verbal communication (Donald, 1991; Dunbar, 1996). 'Gossip' is perhaps the most common form of narration. It is also extremely widespread, making up a large proportion of social communication, apparently taking up 60 to 70 percent of conversation time (Dunbar, 1996; Emler, 1992). Some psychologists conjecture that gossip may have had evolved in order to police cheating within ancestral social groups (Cosmides \& Tooby, 1987; Emler, 1992; Enquist \& Leimar, 1993).

Haskell, a cognitive psychologist, independently identified many of the same narrative phenomena mentioned by Langs (e.g. Haskell, 1987, 1988, 1989a, 1989b, 1991, 1999a, 1999b, 2001) as well as other unconscious semantic structures, such as the role of numbers and homophony in narrative communication. Haskell's data is derived primarily from the observations made in T-groups and naturalistic conversational settings. He has developed a complex model of how a complex array of unconscious cognitive and psycholinguistic operations are used to select and manipulate narrative images which, when introduced into ordinary conversations, carry unconscious meaning. Haskell refers to this as 'subliteral' communication.

Whatever our disagreements, Langs, Haskell and I (e.g. Smith 1991, 1998, 1999) agree on four crucial points:

1. Subliteral communications are vehicles for messages of a kind that are not normally tolerated in polite conversation. To speak subliterally is to speak the unspeakable. The meaning of subliteral communications violates social taboos, but their form disguises this fact.

2. Subliteral communication is unconscious. Even in very transparent examples, the speaker is liable to deny that they had any such thing in mind.

3. Subliteral communication is lawful. The unconscious selection of narrative imagery covaries with events occurring in the immediate conversational setting. 
4. Subliteral communications are particularly responsive to the fundamental structure of the conversational setting, and to biologically significant variables active within that setting (e.g. dominance, cheating, resources, sex, coalitions, deception, etc.).

\section{Illustration}

The following is a real although simplified account of a psychotherapeutic session. Although specifically chosen to illustrate some of the processes described above, it is not untypical.

A psychotherapist in private practice suggested to her patient that he increase the frequency of their meetings from one to two sessions per week, on the manifest grounds that he was getting into 'deep' material and the therapist feelt that more frequent appointments will help him work through these issues more effectively. The patient's first response was to say that this sounded like a good idea. He then proceeded to recount the plot of the movie Jaws, which he had recently seen on television, emphasizing the rapacious greed of the shark. Next, he described having seen prostitutes touting for business on the street. Finally, he mentioned that there are many beggars and drug pushers in the area of town frequented by prostitutes.

The therapist's intervention consisted of two elements: (a) a proposed alteration in the parameters of their relationship and (b) an explanation for that alteration. We would expect the patient to unconsciously pay greater attention to (a) than to (b) on grounds of the biological inexpensiveness of words and the likelihood that they were vehicles for the therapist's efforts at deception and self-deception. By the same token, we would expect him to preferentially devote unconscious cognitive resources to the analysis of (b) in order to determine whether it represents a Machiavellian act of social manipulation that is in the therapist's rather than the patient's interests. Finally, we would anticipate that the patient's conscious mind would have a rather naive understanding of the implications of the intervention.

The patient's first response appears to confirm our third expectation, as he shows no indication of conscious suspicion of the motives for the therapist's proposal. This is rather typical of the limited social-cognitive abilities of the conscious mind.

The patient then switched to narrative mode, telling his therapist several stories that are rich in narrative imagery and manifestly (although not subliterally) irrelevant to the immediate conversational context. The first narrative episode describes a vicious and greedy predator, the shark. This story may have been selected because of the patient unconsciously perceived greedy and predatory 
implications in the proposed increase. The second narrative image of prostitutes may subliterally refer to the financial implications of the proposed modification. The patient may unconsciously suspect that the therapist desires to increase the number of weekly sessions out of financial self-interest rather than altruistic concern about his well-being. The third narrative concerning beggars and drug pushers continues to emphasize the therapist's covert financial agenda but may also imply that the patient suspects that the therapist wishes to make him dependent on her. The patient's subliteral analysis of the therapist's intervention is far more incisive, subtle and biologically realistic than his conscious response. It is also strongly biased in favor of the patient's interests, exaggeratedly representing the therapist's possible self-serving pursuit of money as deadly, relentless predation.

Assuming the essential plausibility of the patient's unconscious reading of the therapist's intervention, it is interesting to note that although the therapist's selfdeception, her 'fictitious narrative of intention' (Trivers, 2000: 119), managed to hoodwink the patient's conscious mind, it was powerless to neutralize his unconscious perceptions, supporting the hypothesis that the power of unconscious social cognition may in part be a response to the selection pressure exerted by self-deception in the interest of deceit, and may be the most recent innovation in the long evolutionary struggle between forces of deception and those of deception detection.

\section{Acknowledgements}

I would like to thank my wife Subrena Smith for useful comments on the adaptive functions of unconscious social cognition, which helped me to conceptualize the significance of unconscious perceptual feedback loops, and for her comments on an earlier version of this paper. I would also like to thank Dr. Robert Haskell for his helpful suggestions.

\section{References}

Alexander, R. D. (1975) The search for a general theory of behavior. Behavioral Science, 10: 77-100.

- (1987) The Biology of Moral Systems. New York: Aldine de Gruyter.

Barratt, J. L. (2000) Exploring the natural foundations of religion. Trends in Cognitive

Science, 4(1): 29-34.

Bruner, J. (1986) Actual Minds, Possible Worlds. Cambridge, MA: Harvard University Press.

Bucci, W. (1997) Psychoanalysis and Cognitive Science: A Multiple Code Theory. New

York: Guilford Press. 
Byrne, R. W. (1993) Do larger brains mean greater intelligence? Behavioral and Brain Sciences, 16(4), 696-697.

- (1994) The evolution of intelligence In P. J. B. Slater \& T. R. Halliday (Eds.), The Evolution of Behaviour. Cambridge, England: Cambridge University Press.

Byrne, R. W., \& Whiten, A. (1988) Machiavellian Intelligence: Social Expertise and the Evolution of Intellect in Monkeys, Apes, and Humans. New York, NY: Oxford University Press.

Claxton, G. (1994) Noises from the Darkroom: The Science and Mystery of the Mind. London: Aquarian.

- (1998) Hare Brain Tortoise Mind. London: Fourth Estate.

Cosmides, L. \& Tooby, J. (1987) Evolutionary psychology and the generation of culture, Part II. Ethology and Sociobiology, 10: 51-97.

Dawkins, R. (1976) The Selfish Gene. Oxford: Oxford University Press.

Dawkins, R. \& Krebs, J. R. (1978) Animal signals: information or manipulation? In Behavioral Ecology: An Evolutionary Approach. J. R. Krebs \& N. B. Davies (Eds.). Sunderland, MA: Sinauer.

Dennett, D. C. (1991) Consciousness Explained. New York: Little, Brown \& Co. Donald, M. (1991) Origins of the Modern Mind. Cambridge, MA: Harvard University Press.

Dunbar, R. (1991) Functional significance of social grooming in primates. Folia Primatologica, 51: $121-131$.

- (1996) Grooming, Gossip and the Evolution of Language. London: Faber and Faber. Ekman, P. (1988) Self-deception and detection of misinformation. In Self-Deception: An Adaptive Mechanism. Lockard, J. S. \& Paulhus, D. L. (Eds.). Englewood Cliffs, NJ.: Prentice Hall.

- (1992) Telling Lies: Clues to Deceit in the Marketplace, Politics and Marriage. New York: W.W. Norton \& Co.

Emler, N. (1992) The truth about gossip. Social Psychology Newsletter, 27: H-3T. Enquist, M. \& Leimar, O. (1993) The evolution of cooperation in mobile organisms.

Animal Behaviour, 45: 747-757.

Freud, S. (1912b) Recommendations to physicians practicing psycho-analysis. S.E., 12.

- (1913a) The disposition to obsessional neurosis. S.E., 12.

- (1913b) Totem and taboo. S.E., 12.

Hamilton, W. D. (1963) The evolution of altruistic behaviour. American Naturalist, 97: 354356.

Haskell, R. E. (1987) Social cognition and the non-conscious expression of racial ideology, Imagination, Cognition and Personality. 6 (1) 75-97.

- (1988) Small group «fantasy theme» analysis: Anthropology and psychology:

A comparative study of a psychosocial structure of a ritual ceremony. Journal of Psychohistory, 16: 61-78.

- (1989a) Analogical transforms: A cognitive theory of the origin and development of equivalence transformation, Part I. Metaphor and Symbolic Activity, 4, 247-259.

- (1989b) Analogical transforms: A cognitive theory of origin and development of enuivalence transformation Part II Motanhor and Svmholic Artivitu 4 557-777 
- (1991) An analogical methodology for the analysis and validation of anomalous cog nitive and linguistic operations in small group (fantasy theme) Reports. Small Group Research, 22: 443-474.

- (1999a) Between the Lines: Unconscious Meaning in Everyday Conversation. New York: Plenum/Insight.

- (1999b) Unconscious communication: Communicative psychoanalysis and subliteral cognition. Journal of the American Academy of Psychoanalysis, 27(3): 471-502.

- (2001) Deep Listening: Hidden Meanings in Everyday Conversation. Cambridge, MA: Perseus.

Humphrey, N. (1976) The social function of intellect. In R. Byrne and A. Whiten (eds.) Machiavellian Intelligence. Oxford: Oxford University Press.

Langs, R. J. (1978) The Listening Process. New York: Jason Aronson.

- (1979) The Therapeutic Environment. New York: Jason Aronson.

- (1980) Interactions: The Realm of Transference and Countertransference. New York: Jason Aronson.

- (1981) Resistances and Interventions: The Nature of Psychotherapeutic Work. New York: Jason Aronson.

- (1985) Madness and Cure. Emerson, NJ: Newconcept Press.

- (1992a) Science, Systems and Psychoanalysis. London: Kamac.

- (1992b) A Clinical Workbook for Psychotherapists. London: Kamac.

- (1995) Clinical Practice and the Architecture of the Mind. London: Kamac.

- (1996) The Evolution of the Emotion Processing Mind. London: Karnac.

Miles, H. L. (1986) How can I tell a Lie? Apes, language and the problem of deception. In R. W. Mitchell \& N. S. Thompson (eds.) Deception: Perspectives on Human and Nonhuman Deceit. Albany: State University of New York Press.

Otte, D. (1975) On the role of intraspecific deception. American Naturalist, 109: 239-242. Smith, D. L. (1991) Hidden Conversations. London: Routledge.

- (1998) Ferenczi, Langs and scientific reasoning: A reply to Martin Stanton. British Journal of Psychotherapy, 14(3): 348-352.

- (1999) Getting our act together: lessons on meaningful psychotherapy research from the philosophy of science. Journal of Clinical Psychology, 55(12): 1495-1506.

Trivers, R. (1971) The evolution of reciprocal altruism. Quarterly Review of Biology, 46: 3556.

- (1976) Foreword. In Dawkins, R. The Selfish Gene. Oxford: Oxford University Press.

- (1985a) Social Evolution. Menlo Park, CA: Benjamin/Cummings.

- (1885b). Interview. Omni, July, 1985, p. 111.

- (1981) Sociobiology and politics. In E. White (Ed) Sociobiology and Human Politics. Lexington, MA: Lexington Books.

- (1988) Introduction. In J. S. Lockhard \& D. L Paulhus (Eds.) Self-Deception: An Adaptive Mechanism? Englewood Cliffs, NJ: Prentice Hall.

- (1991) Deceit and Self-Deception: The Relationship between Communication and Consciousness. In Robinson, M. H. and Tiger, L. (Eds) Man and Beast Revisited. Washington: Smithsonian Institution Press.

- (2000) The elements of a scientific theory of self-deception. Annals of the New York Academy of Sciences, 907: 114-131. 
de Waal, F. (1986) Deception in the natural communication of chimpanzees. In Deception: Perspectives on Human and Nonhuman Deceit. R. W. Mitchell \& N. S. Thompson (eds.). Albany: State University of New York Press.

Whiten, A., Byrne, R. W. (1988) Tactical deception in primates. Behavioral and Brain Sciences, 11, 233-273.

- (eds.) (1997) Machiavellian Intelligence II: Extensions and Applications. Cambridge: Cambridge University Press

Wickler, W. (1968) Mimicry in Plants and Animals. New York: McGraw-Hill. Wrangham,

R. \& Peterson, D. (1997) Demonic Males: Apes and the Origins of Human Violence. London: Bloomsbury. 